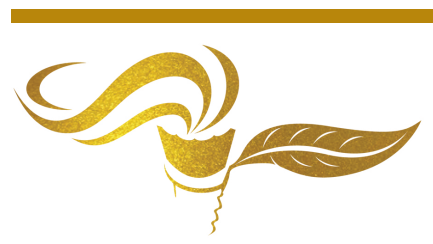

\title{
Being in the Hidden Third: Insights into Transdisciplinary Ontology
}

\section{Sue L. T. McGregor ${ }^{1}$ and Paul Gibbs ${ }^{2}$}

${ }^{1}$ McGregor Consulting Group 11566 Peggy's Cove Road Seabright, Nova Scotia, Canada B3Z 2Y1, emials: sue.mcgregor@msvu.ca; www.consultmcgregor.com

${ }^{2}$ Azerbaijani, East European and Middlesex Universities Middlesex University, Department of Education The Burroughs, Hendon London, England NW4 4BT, email: P.Gibbs@mdx.ac.uk

Received 20 July, 2020; Revised 18 August, 2020; Accepted 18 August, 2020

Available online 19 August, 2020 at www.atlas-journal.org, doi: 10.22545/2020/00139

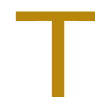

his paper reflects two transdisciplinary (TD) scholars' attempts to glean deeper insights into Nicolescu's transdisciplinary ontology (i.e., multiple Levels of Reality and the Hidden Third). Respecting that Nicolescu's Hidden Third represents the convergence of quantum physics, philosophy, and inner experiences, one TD scholar explored 'What is it like to be in the Hidden Third?' by expanding on Nicolescu's constructs of cyber-space-time and transhumanism, which are grounded in quantum physics. The other TD scholar tendered philosophical insights by offering the idea of ontological emergence and the act of becoming as informed by the transcendentals. The intent was to understand 'the being of being' or perhaps 'the being of becoming.' The richness of Nicolescu's ontological thinking offers a range of interpretation, and we are grateful for the opportunity to feed off his methodological genius to respectively flourish through questions, clarification and truth seeking.

Keywords: Transdisciplinary ontology, cyber-space-time, transhumanism, ontological emergence, the transcendentals.

\section{Introduction}

In his formulation of a transdisciplinary methodology (i.e., a new way to create knowledge), Nicolescu $(1985,2002,2016)[1,2,3]$ conceptualized the Hidden Third as the anchor of his formulation of ontology (i.e., reality, being, becoming, existence, existing). He considered the Hidden Third to be the spirit-opening, lubricating and unifying force that brings together divergent minds to address complex issues. During an email exchange (May 28, 2020) about a paper Paul Gibbs was writing about transcendentals and the unity of being, Paul serendipitously used the phrasebeing in the Hidden Third. Sue L. T. McGregor took this to mean 'What is it like to be in the Hidden Third?' Paul had actually meant, philosophically, "the being of being.' This paper emerged from our subsequent transdisciplinary (TD) conversations and collaboration.

It shares our respective musings about the Hidden Third, "which is at the same time scientific and philosophical" (Tavares, 2016, p. 9 [4]). The Hidden Third is "a point of convergence between quantum 


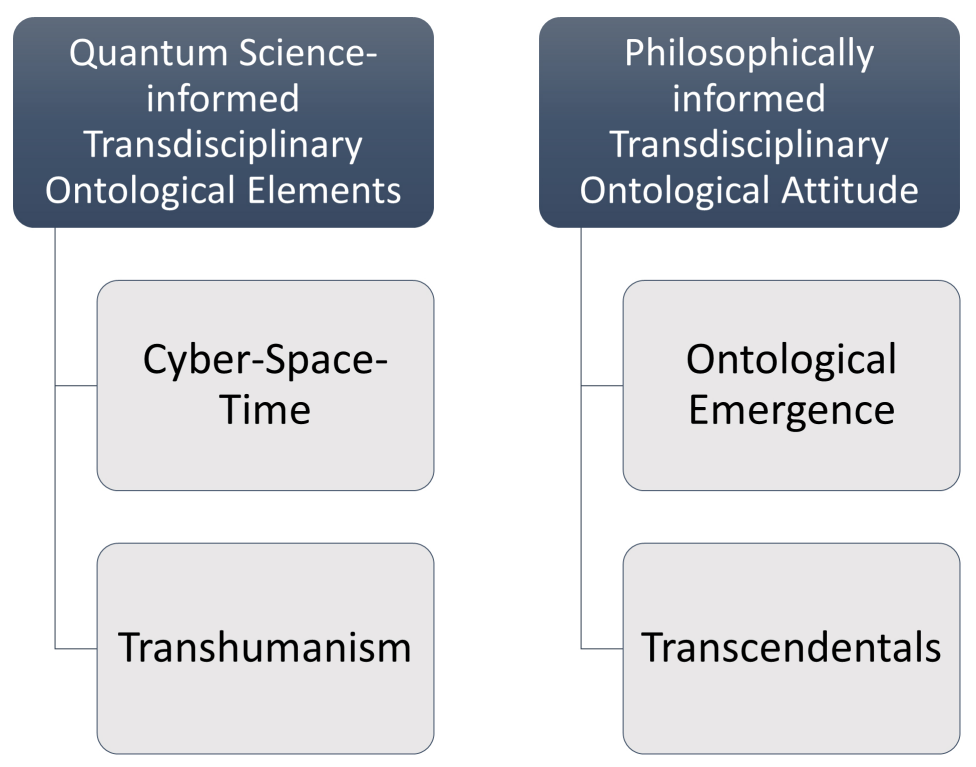

Figure 1: Quantum science and philosophically informed augmentations of Nicolescuian transdisciplinary ontology.

physics, Philosophy of Nature and inner experience" (Tavares, 2016, p. 9 [4]). We agree with Tavares' (2016) [4] premise that encountering the phrase being in the Hidden Third was "the inception of a process where the greatest quantity of a substance is concentrated, something the development of that process is only going to dilute" (p. 10). We accept Tavares' (2016) caution that our attempts to explore what this phrase meant to each of us might dilute the power of the original phrase, which inspired us in the first place. But we offer this paper in anticipation that it will help others engage with Nicolescu's ontology, which is the most misunderstood aspect of his methodology. Resistance to his formulation of ontology has created "an unconscious barrier to a true dialogue" about transdisciplinary methodology (Nicolescu, 2010b, p. 23) [5].

The paper begins with a succinct orientation to Nicolescu's formulation of transdisciplinarity, which is augmented with a detailed discussion of his ontology. This is followed with Sue's thoughts on 'What is it like to be in the Hidden Third?' Her contributions herein reflect quantum physics per Tavares' (2016) [4] suggestion that the Hidden Third is partly understood through science. Having teased out other aspects of Nicolescuian ontology in another paper (McGregor, 2011) [6], she focused on cyber-space-time and transhumanism herein thereby extending two additional ontological elements. By sharing his thoughts on 'the being of being,' Paul tendered philosophical insights into the Hidden Third (per Tavares, 2016) [4]. He offered the idea of ontological emergence and the act of becoming as informed by the transcendentals - an ontological attitude (see Figure 1).

\section{Overview of Nicolescuian Transdisciplinarity}

When formulating transdisciplinarity, Nicolescu (2002) [2] used three philosophical axioms: (a) reality comprising the TD-Object, TD-Subject, and the Hidden Third (ontology); (b) knowledge as complex, emergent, cross fertilized and embodied (epistemology); and (c) logic (inclusive and complexity). Succinctly, he theorized that today's complex problems cannot be adequately addressed using fragmented mono, multi or interdisciplinarity, because these are constricted to the academy (respectively, one academic discipline, more than one, or between two or more). Complex issues like climate change and unsustainability can only be responsibly addressed by drawing on knowledge generated at the interface of university academic 

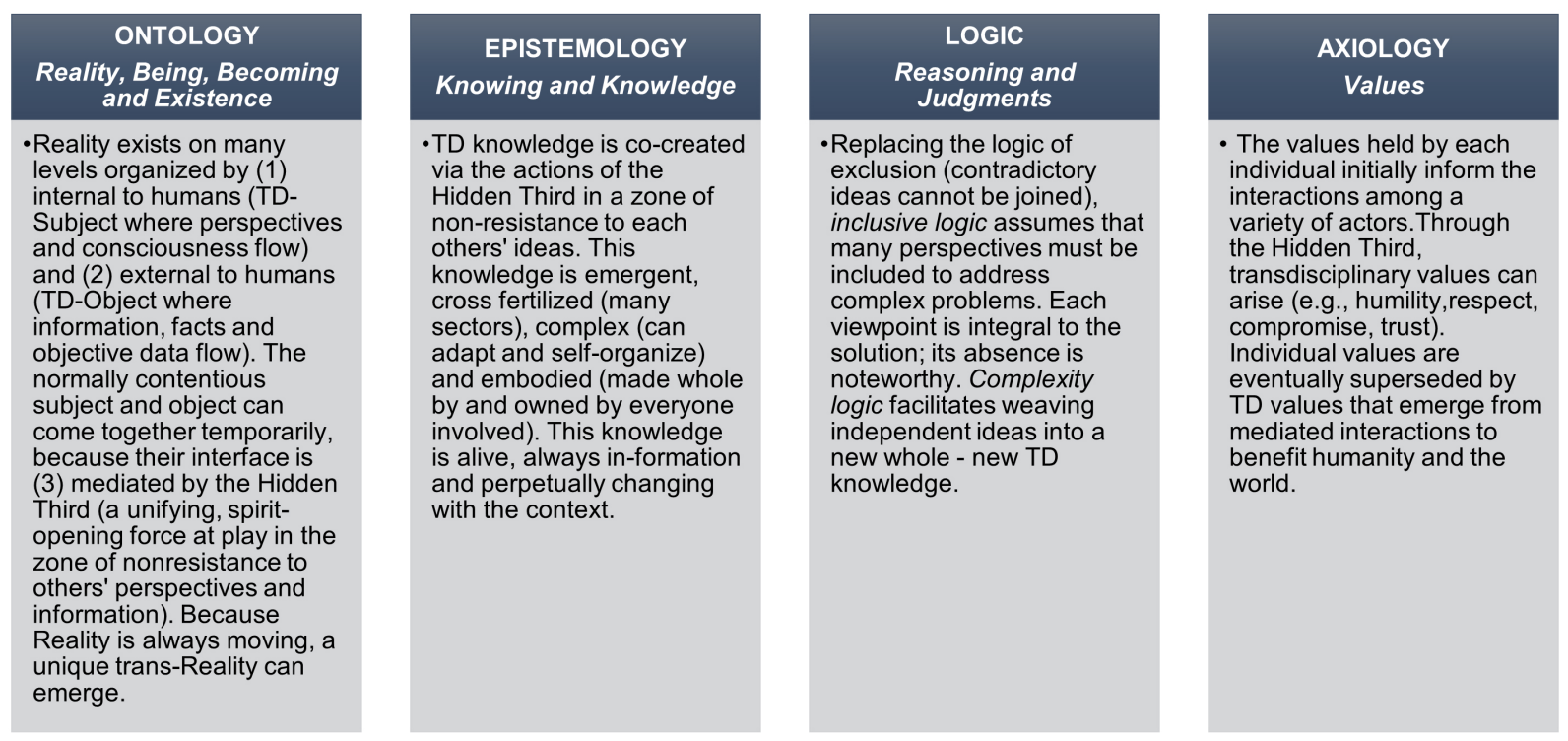

Figure 2: Nicolescuian transdisciplinary axioms.

disciplines and the rest of the world (e.g., civil society, governments and businesses).

This approach respects the need to realign the sciences with humanity (Nicolescu, 2014) [7]. But the diverse nature of these sectors opens the door to extreme challenges in bringing such disparate mindsets together to address a problem. To accommodate the complexity of this knowledge creation process, Nicolescu tendered revolutionary formulations of what counts as reality, knowledge, and logic (reasoning, judgements and insights) (see Figure 2 and McGregor, 2018, [8] for a detailed overview). This paper concerns ontology (reality) and was prompted by Paul's turn of phrase being in the Hidden Third.

\subsection{Transdisciplinary Ontology}

Succinctly, Nicolescu (2002) [2] postulated that instead of one reality waiting to be discovered using the scientific method, there are multiple levels of Reality (he capitalizes Reality) organized along two levels (see Figure 3). One level concerns subjective Reality (TD-Subject), so called because it deals with the internal flow of perspectives and consciousness. Included are individual psychology and philosophy, family, community, society, history, and political ideologies. The other level concerns objective Reality (TD-Object), so called because it deals with the external flow of information, facts, statistics and empirical evidence. Examples include economics (business and law), technology, science and medicine, ecology and environment, planetary (worldwide and global), and cosmic and universe (Nicolescu, 2002, [2] 2014) [7].

Each level of Reality is different, but "every level is what it is because all of the levels exist at the same time" (Nicolescu, 2014, p. 207) [7]. For example, every economic system is different, but a particular economy is what it is because of the political, geographical and technological realms within which it is embedded. Also, "studies of the universe [TD-Object] and the human being [TD-Subject] sustain one another" (Nicolescu, 2014, p. 208) [7]. Respectively, knowledge is at the same time exterior and interior; it is not one or the other nor is one more privileged than the other (Nicolescu, 2014) [7]. An inclusive, integrated knowledge is needed to address complex problems, and the creation of that knowledge requires both subjective and objective Realities.

To deal with complex problems, people must come together and interact. Such a problem might be building a new dam that will flood certain communities but provide power to the entire nation. Nicolescu (2002) [2] recognized the real possibility of tension, antagonism and contradiction among people during 

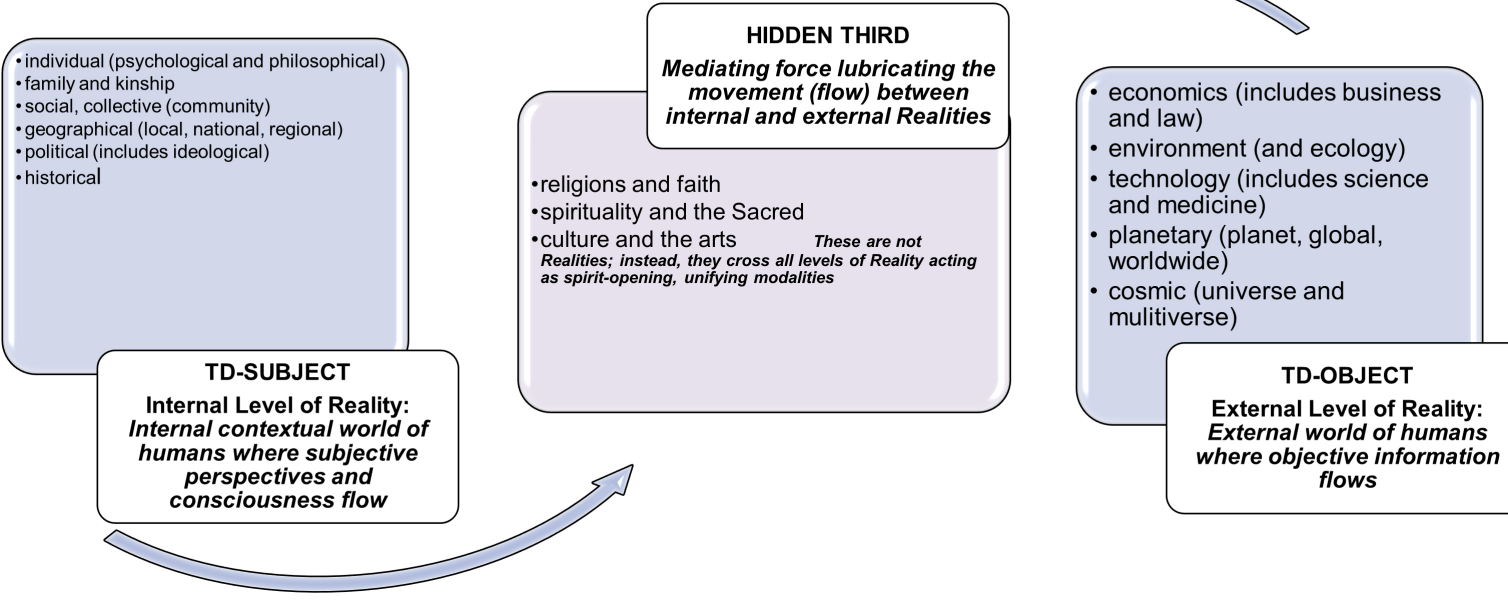

Figure 3: Nicolescuian transdisciplinary ontology.

these interactions. To accommodate this aspect of creating transdisciplinary knowledge, he formulated the new notion of entering a zone of nonresistance to each other's ideas (the so-called neutral, included middle ground). He suggested that tensions created by movement between and along the many levels of conflicting subjective and objective Realities (see Figure 3) can be mediated by the Hidden Third (Nicolescu, 2002) [2]. This was his name for the unifying modalities that open people's minds to others' ideas (Eric Reynolds, personal communication, August 15, 2018).

The Hidden Third (like a middleman in a contentious negotiation) comprises art, culture, religion, faith, spirituality, and the Sacred (i.e., a sense of everything being connected) (Nicolescu, 2002) [2] (see Figure 3 ). It is well established that these creative and mind-opening outlets can successfully be used to build a shared identity and common purpose that transcends differences and conflicts (Bergh \& Sloboda, 2010) [9].

In a recent paper, Nicolescu expanded on his explanation of TD ontology by referring to the TD-Object as "natural information" and the TD-Subject as "spiritual information" (Versluis \& Nicolescu, 2018, p. 17) [10]. Natural information (external to humans) can be measured using instruments or experiments, but people experience spiritual information in their interiority (i.e., their inner thoughts, feelings, reactions). The TD-Subject is internal to humans, and its existence is totally dependent on the mind (McGregor, 2018) [8]. Both natural and spiritual information share the zone of nonresistance. Because of the unifying effect of the Hidden Third, the mediated flow of both natural and spiritual information across different levels of Reality can lead, respectively, to "the fusion of knowledge and being" (Versluis \& Nicolescu, 2018, p. 19) [10].

In order to navigate the diversity of positions and values brought to the table in the zone of nonresistance, Nicolescu (2002) [2] recommended using inclusive logic. This replaces exclusive logic, which assumes that antagonistic and contradictory ideas cannot be connected - an idea expressed through either/or thinking (Brenner, 2008) [11]. Inclusive logic assumes instead that "that which appears to be disunited is united, and that which appears to be contradictory is perceived as noncontradictory" (Nicolescu, 2008b, p. 7 [12]). This represents and/or thinking. Nothing is excluded up front, because it may be necessary for the solution or the process of getting to the solution. Employing inclusive logic when contradictory ideas interact can better ensure a temporary resolution of antagonism, so that something new can emerge. 


\section{What is it Like to Be in the Hidden Third?}

Via the Hidden Third, barriers come down between people and minds are opened, so something new can emerge. In an earlier, far-reaching exploration of TD ontology, Sue (McGregor, 2011) [6] had discovered Nicolescu's formulation of multiple levels of Reality, which he theorized are plastic, malleable and always moving (Nicolescu, 2008a) [13]. "Reality cannot be reduced to substance; instead, reality is the complexus (an aggregate) of substance-energy-space-time-information" (McGregor, 2011, p. 7 [6]). Movement among these five elements is constant, meaning it is impossible to arrive at an exact and complete portrait of Reality (Nicolescu, 2008a) [13].

However, through people's interactions in the zone of nonresistance mediated by the Hidden Third, a new Reality (called trans-Reality) is created for each complex problem being addressed. To explain, if TD-Subject is one circle and TD-Object is another circle, trans-Reality is the point (x marks the spot) where their edges touch. Trans-Reality is beyond all Realities, yet it exists at the same time (Nicolescu, 2002 [2], 2014 [7]). In this paper with Paul, Sue has augmented her understandings of what it is like to be in this space by exploring two additional elements used by Nicolescu (1999 [14], 2002 [2], 2014 [7]): cyber-space-time and transhumanism. What follows is her personal understanding of these two concepts informed by iterative readings of and musings over Nicolescu's scholarship. Any erroneous interpretations (i.e., Nicolescu unintended) are her own.

\subsection{Cyber-Space-Time}

Nicolescu's $(2002,2014)[2,7]$ notion of cyber-space-time (CST) is of relevance to a discussion of 'What is it like to be in the Hidden Third?,' because he identified CST as a key aspect of the logic of the included middle, which people use in the Hidden Third. By way of background for CST, classical physics (general relativity) respects the four-dimensional space-time continuum. It "fuses the three dimensions of space and the one dimension of time into a single four-dimensional manifold" ("Spacetime," 2020, para. 1 [15]). This "mathematical model joins space and time [past, present and future] into a single idea called a continuum" ("Spacetime," 2020, para. 1 [15]), which is Latin continuus, 'uninterrupted' (Harper, 2020) [16]. The space-time continuum concerns the continuity of time (i.e., an unbroken, consistent existence), which is considered linear and moves in a straight line. There is a beginning, the passage of time and an end. Humans mark linear time by using clocks, calendars and day planners (Gibbs, Ylijoki, Guzmán-Valenzuela, \& Barnett, 2014 [17]; Nicolescu, 2014 [7]).

The space-time continuum holds that time and space are closely linked and are even used to define each other. To illustrate, space is Latin spatium, 'a period or stretch of time' (Harper, 2020) [16]. H. G. Wells (1895) [18] said, "Time is only a kind of Space" (p. 10). Time and space are also thought to be smooth and continuous - no disruptions (Nicolescu, 2014) [7]. Pragmatically, "one cannot pass from one point of space and of time without passing through all intermediate points" (McGregor, 2011, p. 2 [6]) (i.e., no reversals, exceptions or skipped stages). Imagine time as marked by a clock; one cannot go back or skip any hours or minutes. To address a complexly wicked problem using this conceptualization of space-time, people would follow a series of steps or formulae, likely ineffectively.

Conversely, quantum physics (i.e., the theory of quantum mechanics) assumes that space-time is not always continuous (Nicolescu, 2014) [7]. In contrast, discontinuous (i.e., intervals, gaps, interruptions) means that, between two points, there is a gap of potentialities (McGregor, 2011) [6]; in other words, there is a quantum vacuum, which is at its lowest level of energy, but it is not empty [7]. Things can arise in this gap (Paul philosophically discusses things).

In more detail, when addressing a complex problem, people would remain open to possibilities and emergence while respecting the power of interruptions and bifurcations (i.e., branching off in different directions). They would eschew the principle of continuity (linearity) and remain open to nonlinearity (i.e., not sequential, not straight forward, not smooth progress forward). When nonlinearity is present in complex thinking scenarios, the dynamic can become quite chaotic (unpredictable) with the assumption that order is emerging just not predictably (Liang, 2017) [19]. For Nicolescu, discontinuity (i.e., the gap) "reflects the 
dark light of the unknown that paradoxically cooperates with the known by injecting information [i.e., new light] into the Kosmos" (personal communication, January 10, 2011).

Respecting discontinuity (i.e., the presence of gaps and interruptions) instead of continuous space-time, transdisciplinarity engages with discontinuous cyber-space-time (CST) (Nicolescu, 2002, 2014) [2, 7]. Cyber is a word-forming element from cybernetics, which is the theory and study of communication and control (Harper, 2020) [16]. Cyberspace is the notional (in the mind only) environment in which communication over computer networks occurs (Anderson, 2014 [20]; Mihalache, 2002 [21]). A contemporary example is the Internet, which is also called cyberspace (Gálik \& Tolnaiová, 2019) [22]. Indeed, the networked computer (cyberspace) represents a ubiquitous logic that has transformed and connected virtually all aspects of the global economy, culture and society (Gibbs et al., 2014) [17]. But the term cyberspace is being used in other areas beyond the Internet as in this instance by Nicolescu.

First coined in the early eighties, adding the word cyber to space-time was a way to capture the phenomenon of a previously nonexisting space that emerges in the process of communication and development (Gálik \& Tolnaiová, 2019 [22]; Mihalache, 2002 [21]). From a transdisciplinary perspective, put simply, as people engage in the zone of nonresistance mediated by the Hidden Third, a new space is born, which Nicolescu (2002) [2] called cyber-space-time. He proposed that inclusive logic is at work in this space, which is "the transcultural, transnational and transpolitical ... space of human choice" (Nicolescu, 2002, p. $82[2]$ ); that is, people choose to work with disparate minds (e.g., cultures, nations, politics) and strive to move beyond all of them to a new space within which to address a complex problem.

Nicolescu (2002) [2] further argued that, beyond assuming that cyber only means technology, bringing the human into cyber-space-time "alerts us to a new level of perception..., which reveals a world that breaks radically with the macrophysical world in which we pass our life. This 'new world' is not ruled by classical logic" (p. 79) (see also Gibbs et al., 2014 [17], who said cyberspace has its own logic). Instead, Nicolescu (2002) [2] formulated that moving around CST requires people to use inclusive logic to navigate interactions between subjective and objective worlds much like they would use nonlinear logic to navigate the Internet (e.g., Boolean searches using and/or).

Nicolescu (2002) [2] considered cyber-space-time a connecting principle that bridges mind (TD-Subject) (perceptions and consciousness) and matter (TD-Object) (facts, evidence, statistics) to make levels of perception more evident as people cross realities and communicate. In the Hidden Third, "time and space [are] linked by a relationship of contradiction" (Nicolescu, 2014, p. 132 [7]). Brenner (2003) [23] described CST as a "currently emergent level of reality" (p. 173). Nicolescu (2008a) [13] similarly described Reality as always moving, always fluctuating - hence emerging and becoming.

In this emergent reality, space is no longer viewed as smooth as in the classical space-time continuum. Instead, space in CST is depicted as spacetime foam (Wheeler, 1955) [24] or "quantum foam to describe the turbulence [and tension]" (Nicolescu, 2014, p. 67 [7]) among people as they strive to assimilate divergent views on a pressing matter. Instead of linearly moving through the "distance between points" (continuity) (Nicolescu, 2014, p. 68 [7]), people would move through a complex and turbulent space comprising a mass of small, transient (quantum) bubbles. Thus, CST comprises many small, ever-changing regions. Therein, space and time are not definite but fluctuate in a foam-like manner (Wilczek, 2010) [25]. When addressing complex problems, these small bubbles could represent emergent and evolutionary pockets of conversations, coming and going as the problem, people and knowledge evolve.

Another notable characteristic of CST is that it is simultaneously artificial and real just with different degrees of materiality (Nicolescu, 2002) [2] - in other words, it is more than dualistic 'either artificial or real.' Also, within this space, there is a close relationship between the material (matter, artifacts) and the cognitive (mind, intelligence) (Lemos \& Kern, 2009). [26] This premise aligns, respectively, with Nicolescu's (2002) [2] TD-Object and TD-Subject.

CST is also viewed as a network of collective intelligence characterized by hyperconnectivity (Lemos \& Kern, 2009) [26]. If something is hyper, it is unusually energetic and maybe excessive (Anderson, 2014) [20]. Hyperconnectivity within cyber-space-time assumes that people who need to communicate will and do communicate (Ranadivé, 2003 [27]; Wellman, 2003 [28]). Cyber-space-time is thus an immersive environment of social communication (Lemos \& Kern, 2009) [26] that depends on networks (Ranadivé, 
2003) [27].

Madni (2019) [29] further linked hyperconnectivity with both growing complexity and an increasing convergence among academic disciplines. The same holds for Nicolescu (2002) [2] who focused on complexity and envisioned the convergence of disciplines with the life world. The verb converge means coming together from different directions to eventually meet (Anderson, 2014) [20]. This is exactly what happens in the zone of nonresistance, where people open themselves to others' perspectives and information, a process that is mediated by spirit- and mind-opening aspects of the Hidden Third (e.g., art, theatre, music, drama, faith, culture).

In summary, "cyber' space is a ritually created space of liminality with transformative properties" (Barbatsis, Fegan, \& Hansen, 1999, last paragraph [30]). To break this down, rituals (i.e., habitually followed series of actions) can be used to create relations among people, and subsequent relations help to constitute the whole. A ritually created space emerges from rituals (Iteanu, 1990) [31]. A liminal space is barely perceptible - neither here nor there. When people enter it, they stand on a threshold, where something can cease to exist or can come into existence; it transforms (Turner, 1974) [32].

Respectively, in summation, when addressing complex problems, diverse people can operate within a ritually created space (CST) as they temporarily set aside their way of viewing things, cross the threshold and step into the liminal space (i.e., the zone of nonresistance mediated by the Hidden Third) where perspectives, consciousness and information can transform and be integrated into new knowledge using inclusive and complexity logics (Nicolescu, 2002, 2014) [2, 7].

Sue proposes that cyber-space-time and what it constitutes is part of what it is like to be in the Hidden Third. Another element related to being in the Hidden Third is transhumanism. Tirosh-Samuelson (2007) [33] asserted that "transdisciplinarity... captures the new state of affairs in human knowledge as much as transhumanism captures the new human condition" (p. 3).

\subsection{Transhumanism}

Nicolescu (1999) claimed that cyberspace allows the advent of a new humanism. In the spirit of transdisciplinarity, he called this transhumanism. By way of background, humanism (sans trans) is a thought system that attaches importance to humans instead of the divine or supernatural (Anderson, 2014; Rohmann, 1999) $[20,34]$. This $17^{\text {th }}$ century philosophical movement held that people should rely on their own observations and judgments instead of deferring to religious authorities to interpret life for them (Bostrom, 2005) [35].

Transhumanism is conventionally thought to be a subsequent $20^{\text {th }}$ century philosophical movement focused on transforming the human condition by using technology and science to enhance both human intellect and physical attributes. People would use science and technology to evolve beyond their current physical and mental limitations (Bostrom, 2005 [35]; Tirosh-Samuelson, 2007 [33]). The crux of this conceptualization of transhumanism is the role technology plays in humanity's evolution (Tirosh-Samuelson, 2007) [33]. As a caveat, Nicolescu (2014) [7] would caution that humans should harness technology and science rather than be enslaved by them. Without due care, their use can negatively impact humanity and snare and enframe nature in the service of humans thus distorting Reality.

Indeed, when Nicolescu (1999) [14] linked cyber-space-time with transhumanism, he expanded its meaning beyond human physical and intellectual transformation via technology and science. He comprehensively viewed transhumanism as offering "each human being the maximum capacity for cultural and spiritual development" (Brenner, 2003, p. 177 [23]) (Paul addresses human potential and development as well). Eminent psychologist Abraham Maslow (1969) [36] positioned transhumanism at the top of his hierarchy of human needs by placing it above self-actualization. Cerma (2008, p. 167 [37]) explained that Maslow viewed transhuman as "centered in the cosmos" instead of in human needs. Maslow assumed that humans can place universal values like justice and rights above meeting their own needs (Koltko-Rivera, 1998) [38]. These values liken to Nicolescu's (2010a) [39] position on transdisciplinary values (to be discussed), which are much more than and far beyond each person's self-interest - they are transpersonal as required for transdisciplinary engagement.

Indeed, for Maslow, transhumanism was "a transpersonal approach that focuses on amplified and 
transcendent states of consciousness" (Cerma, 2008, p. 167 [37]). Nicolescu's (2002) [2] formulation of the TD-Subject is intentionally grounded in consciousness (and perspectives), and the Hidden Third deals with spirituality and the Sacred (see Figure 3). Regarding the former, consciousness is an umbrella term for "a wide variety of mental phenomena" (Van Gulick, 2014, p. 4 [40]). It can mean sentience, wakefulness, self-awareness and being aware, or being conscious of something. Consciousness can be a state, a stream or an availability to interact (Van Gulick, 2014) [40]. Nicolescu (2005) [41] believed that the brain and mind encompass different levels of Reality and perception, which is why he placed consciousness in the TD-Subject.

Also, for Nicolescu, spirituality (in the Hidden Third) reflects introspection and interiority; that is, the inner field for transcendence (Versluis \& Nicolescu, 2018) [10]. They explained that people can analyze an object or event to create external knowledge (e.g., chemically analyze an old painting and prepare a scientific report), but through their consciousness (TD-Subject), their interior experience of this object or event is entirely different from the written report.

Nicolescu (2014) [7] held that people cannot fully understand a complex problem (e.g., the painting metaphor) unless there is a connection between inner consciousness and external information; that is, TD-Subject and TD-Object. Respectively, this refers to both viewing and experiencing the painting, reading the scientific report about the painting and then coming to some judgement or assessment. A richer understanding will emerge from their conjoining. And like spirituality, the Sacred (i.e., a deep connection between people, their common life and the Earth) lubricate movement among the different levels of Reality (i.e., consciousness and information) (Nicolescu, 2014) [7]. That connection is more likely, if people can appreciate the power of and be motivated by Nicolescu's (1999) [14] formulation of transhumanism.

Indeed, transhumanistic refers to "a motivational state in which the person seeks something beyond personal benefit" (Koltko-Rivera, 2006, p. 305 [42]); that is,transpersonal. Transhumanism concerns situations where a person is "motivated by values which transcend his [sic] self' (Maslow, 1969, p. 4 [36]). Maslow (1969) [36] called these "transcendent values, [because they are outside (beyond) a person and are focused instead on] ultimate verities [such as] truth, goodness... justice or order" (p. 3). Put simply, people would temporarily set aside their own needs and self-interest for some higher cause (Koltko-Rivera, 2006) [42].

Similarly, Nicolescu (2010a) [39] maintained that transdisciplinary values arise from work undertaken through the Hidden Third to address complex, wicked problems; in effect, a higher cause than self-interest. Nicolescu does not have a fourth axiology axiom, although Figure 2 does include it, so readers can appreciate his understanding. He asserted instead that emergent transdisciplinary values are what matter not the values people hold initially when they enter the zone of nonresistance to address the complex problem.

Rather, being in this space means respecting the emergence of specific values that are integral to generating new knowledge for a particular complex problem. Integral means they are necessary for completeness. Their absence would be notable. The new knowledge that does emerge is dependent on particular TD values engendered via the Hidden Third (McGregor, 2018) [8]. Examples of TD values that motivate people to work toward a cause higher than themself include humility, compromise, trust, tolerance and respect. Jointly agreeing that these values are important helps the work get done, so that new knowledge can arise.

In summary, unpacking cyber-space-time and transhumanism offers a clearer picture of how Nicolescu understood ontology. Cyber-space-time offers interconnectivity, the necessity and power of networking, and the principle that those who need to communicate with each other will do so. It frames transdisciplinary work as comprising many small, ever-changing regions whose navigation must be facilitated. The resultant work arising within these networks (small bubbles) is described as collective intelligence.

Cyber-space-time also serves as a bridge (i.e., interconnection) between mind (TD-Subject) and matter (TD-Object). It moves people through relationships that are rife with contradictions and possibilities by helping them better appreciate divergent perspectives on the problem. People are seen as stepping onto and across a threshold, where transformation leads to the emergence of new knowledge to address the complex problem.

Transhumanism enables those interested in TD ontology to assume that people can temporarily set 
aside their personal needs for a larger, higher cause. They can become open to suspending their self-interest and personal gain, so the divergent group of agents can focus on universal truths such as peace, order, rights, justice and sustainability. Transhumanism also offers the idea of amplified states of consciousness, which strengthen the work of the Hidden Third.

Harken to the example of building a new dam that will flood certain communities but provide power to the entire nation. Transhumanism assumes people can move beyond themselves for the greater good - the higher cause. Conversations among those affected by the dam issue will have to address what that higher cause might be and work to that valued end - from a transpersonal space. The higher cause might be the nation, or it might be the impacted communities. Regardless, it is greater than (transcends) one person's self-interest.

\section{The Being of Being}

The Hidden Third transforms TD-Object and TD-Subject into a respective "fusion of knowledge and being" (Nicolescu, 2014, p. 212 [7]). Paul is philosophically interested in the being part of this fused state. In his own words: my philosophical approach to 'the being of being' hinges on Nicolescu's (2008a) [13] formulation of TD ontology (reality and being) with Reality constantly in flux, plastic and malleable. But not only is Reality always changing - so are the people engaged in TD work to co-create a new trans-Reality replete with co-created TD knowledge (McGregor, 2004) [43].

Paul believes that the pervasive transdisciplinary principle of emergence (Nicolescu, 2002) [2] encompasses the notion that we are always in the process of development. Such becoming cannot be adequately described only in deterministic ways as is assumed in mechanistic and scientific analogies of being. This process is primordially transdisciplinary, for it is best explored in its own terms not that of disciplines. I call this ontological emergence. Let me elaborate for your consideration.

\subsection{Actualizing Potential through Ontological Emergence}

In his metaphysics of transdisciplinarity, Nicolescu's (2010b) [5] focus on levels of Reality provides a wholeness in a cosmological process in which being is constantly changing within the Realities that it creates. In accepting his fundamental premise of the ontology of transdisciplinarity, I want to briefly explore an issue that is central to my reading of his ontology: the notion of change that is initiated by causal power, which refers to the likelihood that a cause actually caused the change or the effect (Luhmann \& Ann, 2005) $[44]$.

Instead of how causal power causes change, I am interested in how change in causal powers (passive, active and actualized) is the energizing force that enables our potentiality to flow (evolve and emerge) into the actual. Key to this emergence is potential, which has the Latin root potentialis, 'power' (Harper, 2020) [16]. This causal power is akin to the latent power in the quantum vacuum, which is simmering with unactualized potential. Change enables other Realities that exist beyond the momentum of action and thought to form a temporality (akin to the temporary reconciliation of contradictions in the zone of nonresistance). This temporality enables us to express our becoming in ways that are both rhizoid (i.e., anchors entity and conducts energy) and emergent instead of deterministic or causal in the sense we might ordinarily use the terms.

Much research is required to explore the real occurrence of emergence without being dependent on models of causality (Leavy, 2011) [45] and the avoidance of it without clarity in discussion of transdisciplinarity (e.g., Augsburg, 2014) [46]. Herein, I use ontological emergence in a specific transdisciplinary way that complements our common understanding of causality based on generative atomism. Regarding the latter, "there exist atomic entities, be they physical, linguistic, logical, or some other kind, and all else is composed of those atoms according to rules of combination and relations of determination" (Humphreys, 2005, para. 2 [47]). Ontological emergence holds that (a) horizontal structures provide processes where earlier stages of systems are causally responsible for later states (i.e., determinism and continuity) and (b) vertical structures are a layered ontology of Realities (akin to quantum discontinuity and multiple levels of Reality). 
Basically, emergence is not rooted within a single science but is transdisciplinary and appears where a determination model fails to explain a new phenomenon. Something that is ontologically emergent has features that have not been previously observed in the coexistent system and is the result of a dynamic process (see Humphreys, 2016 [48]) resulting in something being autonomous, novel and holistic. It is in this sense that I use the term ontologically emergent.

When I talk of 'the being of being,' I am referring to the first universal that is common to all entities: their being. Birds have being, stones have being, and we, as a genus of beings as human beings, have being. Not only do humans have being, they are always becoming (i.e., beginning to be or turning into something). In order to understand the being that we are, we need to struggle with the notion of being something, a struggle that has troubled philosophers ancient and new. To do a thing within the notion of mortal being creates a problem that medieval philosophers have struggled with especially around the notion of whether our being can be spoken of in the same way as the being of the Divine (the eternal). Or do we need to identify whether there are commonalities of terrestrial being that may not be applied to eternal being? In trying to resolve these philosophical questions, we need also to deal with a multifaceted set of other issues: causation, emergences, mysteries, Realities and God(s) and Goddesses.

\subsection{Transcendentals and Actualizing Potential}

From the beginning, we are thrown into this world as we are taught it exists, yet we can free ourselves from the constraints of its structure by seeing the world as it might be for ourselves as we become. This is done not through the methodologies and calculative thinking of others, academic disciplines or professions but through the oneness exemplified in the onto-theological nature of the transcendentals (Latin transcendens, 'that which surpasses something') (Harper, 2020) [16]. Transcendentals are the objective properties or concepts of being, of all that exists. These properties are called transcendental, because they "exceed in extension all the lower classes into which reality is divided" (Turner, 1911, p. 19) [49].

Of interest to the explanation herein is Saint Thomas Aquinas' (c.1225-1274) five transcendentals: one, thing, something, true and good. These loosely equate to (a) science (truth and logic), (b) religion (goodness and ethics) and (c) the arts (beauty and aesthetics) (Faber, 2011; Goris, 2019) [50, 51]. The latter three are central to Nicolescu's $(2002,2010 \mathrm{~b})[2,5]$ formulation of TD ontology (see Figure 3). The former five transcendentals are a new approach brought to TD ontology in this paper. These concepts of being "add the notions of unity [one], of being in oneself [thing], of being as against other things [something], or being ordered to the intellect [true], and of being ordered to the will [good]" (Faber, 2011, para. 1 [50]). These transcendentals or concepts of being align comfortably with Nicolescu's (2002) [2] formulation of TD ontology, which concerns unity, intellect and knowledge, and people being and becoming while working for the good of something greater than themselves.

In the $13^{\text {th }}$ century, John Duns (commonly called Duns Scotus) (c.1266-1308) introduced his theory of transcendentals. Duns Scotus understood transcendental differently than his predecessor Aquinas (Aertsen, 1998) [52]. Scotus held that the one is undivided but being is not. Rather, being is "predicated on something of which 'one' is not predicated, namely, 'multitude"' (Aertsen, 1998, p. 50 [52]). Nicolescu (2010b) [5] also held that Reality (being and becoming) is not single but comprises many levels whose transcendence and integration can lead to a new trans-Reality.

Duns Scotus' (2005) [53] theory of actuality included the conception of a non-categorical 'individual difference' to produce an account of the individuality of an individual as their haecceitas (the thingness of a thing) (see also Aristotle, 1984) [54]. The distinction between two forms of our species' (a) specific potential (e.g., grow to six feet tall, grow hair, walk upright) and (b) individual potential is considered 'the formal distinction.' Moreover, that which makes us individual cannot, by the nature of its singularity, be categorized at a higher order as in an Aristotelian system of categories while still being part of a species that can indeed so be.

This inability to categorize creates an issue of description, meaning we can only name the individuality by proper name or by indexical pronoun (e.g., she, he, you). This formal distinction is at the core of a desire to focus on the whole person as an individual in ways that reveal to that person their extended 
temporal potential to become. Succinctly, Duns Scotus' position was "that in each individual there is a principle that accounts for its being the very thing it is and a formally distinct principle that accounts for its being the kind of thing it is. The former is its individual differentia, the latter its common nature" (2005, p. 50) [53].

This approach grounded in the transcendentals applies to people engaging with transdisciplinarity via the Hidden Third. Perceiving the potential for action in the form of the realities of the transcendentals is a way of realizing the potential that resides within us to become. This potential capability is an ontological driver of the actuality of becoming what we can desire to be (or may be able to be) cognizant of both the transdisciplinary subject and object as ways of becoming.

In more detail, achievement requires activities full of political, social and economic power, and we make our being feasible (a) by questioning the reality of our everyday experience in the knowledge we have of ourselves and (b) with a preparedness and courage to create new knowledge of ourselves from the engagement. Freedom resides in our choice to act on our potential, and potentialities are aligned with the properties of the haeccetias (i.e., the thingness of a thing) that determine its power to act. Thus, not all the properties of a thing are equally important to the understanding of the specific activities, relationships, commitments et cetera that give meaning to an individual's identity, yet all contribute to an individual's potentialities to realize their potentiality to become.

For people engaged with transdisciplinarity, the exploration of their being provides the potential for them to understand and see their life project - to understand that 'being as our becoming' is not deterministic, but neither is it unencumbered; instead, it requires a blending of knowledges and Realities in order that we might have the power to reflect and deliberate about the impact to be achieved by our actions while creating transdisciplinary knowledge.

Most important, this space-time manifold (i.e., many and various folds) is not static but is in constant motion; it is a flow with complexity and causation. This flow of Realities is conceived as an open system in which possible worlds emerge and Realities are (a) perceived and lost in time and space and (b) dependent on the location of the becoming being. It is in this primary sense of becoming as potentiality, as energy and power, that there is capacity to bring about change in another thing or itself. Effecting this change is paramount to creating new transdisciplinary knowledge.

Aristotle (1984) [54] discussed this extensively in Book $\Theta$ of chapter 9 of Metaphysics. In that work, Aristotle introduced a complementary notion to the identity of the being of a thing fixed in terms of categorical notion of substance, whereby the identity of being can be "distinguished in respect of potentiality and fulfilment, and of function" (1045b, 33) [54] . Nicolescu (2008a) [13] also posited that Reality cannot be reduced to substance, because it is an aggregate. Further, Aristotle's [54] potentiality is evident in two forms: (a) as "a certain motive principle" (1046b, 22) inherent in its being and (b) that of being as agent to be. Aristotle then evoked the notion of fulfilment of our potential and compared it merely as an act of participation or to the full fulfilment of its potential, which, he considered, is doing it well. In this sense, the agent engaged in co-creating transdisciplinary knowledge is compelled to do it well.

This completion (i.e., unity) is linked, I suggest, to the notion of oneness with Being and the oneness of one's own being and is defined by its motivational powers. This premise basically acknowledges that - that what exists potentially is ontologically dependent on what exists actually. Said another way, what emerges during collaborative engagement with transdisciplinarity depends on the people involved and their ability to realize their potential as beings being and becoming (i.e., ontological emergence).

Aristotle (1984) [54] used the term Dunamis to describe this concept considering the idea of possible worlds and their Realities as a way in which all sentient, material and spiritual entities - real and actual are co-created in the process of flow from potentiality to actuality. This includes the process of co-creating TD knowledge, which is mediated by the Hidden Third. This is where the creation of trans-Realities can emerge. This emergence is not grounded in the abstraction of empirical theories but in an experience of engaging in a world reconfigured by the co-creative process of becoming as realization of potentiality through the causal powers of the transcendentals.

This aspect of Aristotle's thinking might be conceived as a space-time manifold (i.e., a chamber branching into several paths or openings) that exists at the convergence of TD-subject and TD-object and 
where, I want to suggest, causal powers creatively deploy themselves to effect change and emergence. The binary logic that Nicolescu (2010b) [5] resisted reduces 'difference' to disqualification and exclusion instead of inclusion and absorption. Absence of the latter mitigates full actualization of human potential while addressing complex problems using transdisciplinarity.

A way of realizing the potential that resides within us to do this, as a capability to become, is to perceive the potential for action in the form of the realities of the transcendentals. This potential capability is an ontological driver of the actuality of becoming what we can desire to be (or may be able to be) while cognizant of both the transdisciplinary subject and object as ways of becoming. The perspective I offer augments Nicolescu's (2008a) [13] premise that trans-Reality cannot emerge unless people actualize their potential. The 'being in being' is in fact new realities emerging through beings becoming more; that is ontological emergence.

\subsection{Power and Ontological Emergence}

Of the many levels of Reality (see Figure 3), social reality has an ontological depth; it comprises things, properties and powers - a triad that has internal unity. Social objects (i.e., things-properties-powers) are the real manifestations of the idealized types used in discourse and the focus for any enquiry including transdisciplinary enquiry. As Fleetwood suggested, these "things-properties-powers are emergent from, but irreducible to, other things-properties-powers. Things have properties and properties ground powers" (2009, p. 353) [55] including causal powers.

Thus, a power of its properties is borne by a thing and, when activated, brings about that thing's becoming in the sense of what it can be. As one thing emerges from other things, so do its properties and powers (Fleetwood, 2009) [55]. This is akin to transdisciplinary knowledge being alive and always in formation and people and the problem itself changing as they work together (McGregor, 2004) [43]. The being people are when they engage with transdisciplinarity has the potential to change into (become) something else. People develop during the transdisciplinary process and arrive as different people than when they started.

Things are structured in various ways, and because of this structure, things possess powers. In most everyday cases, both these things are incomplete, leading to a stasis, a being rather than a becoming, an acceptance of the moderate, which limits the presence of humanity rather than fosters the courage to join the mystical, where "reality is neither apparent to the senses nor obvious to the intelligence" (Merriam-Webster, n.d.) [56]. Rather, reality is becoming, just as the beings creating that reality are becoming what they can be, so that complex knowledge can be co-created.

\subsection{Actualizing Becoming}

On a final note, the conscious power of this change can be determined by thinking differently about the transcendental structure of becoming rather than being, although that is romantic and poetic in its first formation instead of logical and calculative. This power recognizes the world of experiences as existing yet is not constrained by it, and it leads to a new configuration of the world. A new reality is possible, because within the power is a force for change instead of stasis.

People flourish when their potentialities are actualized by the positive emergent powers of the transcendentals. These actualize and can manifest themselves in multiforms shaping the patterning of our ways of becoming and are implicitly linked to an appreciation of the attitude toward the transcendentals shaping our identity. This attitude may well seem from the Other to be inconsistent, yet it is still careful of others, for it is not intended to mirror the reality of other people's worlds but to be an expression of one's personal stance within the wholeness of the cosmos.

It is the identity of the individual (the being), not the sameness, that we share in the Hidden Third. We all share the individual potential to actualize becoming as we engage with transdisciplinarity. Reality and being are not static in transdisciplinary ontology but dynamic and emergent - always becoming. Hence, I proposed ontological emergence as informed by the transcendentals. 


\section{Conclusions}

While Sue's contribution to understanding Nicolescu's transdisciplinary ontology expanded two quantum science-informed elements of transdisciplinarity (i.e., cyber-space-time and transhumanism), Paul extended a philosophical attitude in the form of ontological emergence and the act of becoming as informed by the transcendentals. Together, we offer new lines of thought pursuant to (a) What is it like to be in the Hidden Third?' and (b) 'the being of being' or perhaps 'the being of becoming' in the Hidden Third.

An articulation of the value added to Nicolescu's formulation of ontology was woven into our transdisciplinary contributions. While recognizing that our Nicolescuian ontological thoughts are still evolving, we suggest that our musings have added to contemporary thinking on transdisciplinarity (Gibbs \& Beavis, 2020) [57]. We propose that the richness of Nicolescu's ontological thinking offers a range of interpretation that is itself transdisciplinary thus fulfilling his wish that transdisciplinary thinking continue to always move forward.

Basarab Nicolescu's work provides the framework for exploration as does any truly worthwhile formulation or conceptualization. We have taken advantage of such genius in our attempts to understand the concepts and question ourselves as to their relevance to our interpretation of Nicolescu's transdisciplinary ontology. As academics and transdisciplinary scholars, we need to be free to allow our imagination to feed from the work of others to respectively flourish through questions, clarification and truth seeking. We have sought this through Nicolescu's work and are grateful for it.

Author Contributions: Both authors contributed to this paper. Sue wrote her part. Paul wrote his part, and then Sue pulled it all together via the introduction and conclusions with Paul vetting the final version.

Funding: No funding was solicited for this research.

Conflicts of Interest: There are no conflicts of interest for this thought piece/research.

\section{Acknowledgements}

Both authors are deeply grateful for Basarab Nicolescu's contributions to the creation of and generative energies behind transdisciplinarity.

\section{References}

[1] Nicolescu, B. (1985). Nous, la particule et le monde. Paris, France: Le Mail.

[2] Nicolescu, B. (2002). Manifesto of transdisciplinarity. New York, NY: SUNY Press.

[3] Nicolescu, B. (2016). The Hidden Third [W. Garvin, Trans.]. New York, NY: Quantum Prose.

[4] Tavares, G. (2016). Foreword. In B. Nicolescu, The hidden third [W. Garvin, Trans.] (pp. 9-11). New York, NY: Quantum Prose.

[5] Nicolescu, B. (2010b). Methodology of transdisciplinarity. Transdisciplinary Journal of Engineering and Science, 1(1), 19-38. https://doi.org/10.22545/2011/00021

[6] McGregor, S. L. T. (2011). Demystifying transdisciplinary ontology: Multiple levels of Reality and the Hidden Third.Integral Leadership Review, 11(2). http://integralleadershipreview.com/2011/03/demystifyingtransdisciplinary-ontology-multiple-levels-of-reality-and-the-hidden-third/

[7] Nicolescu, B. (2014). From modernity to cosmodernity. New York, NY: SUNY Press.

[8] McGregor, S. L. T. (2018). Philosophical underpinnings of the transdisciplinary research methodology. Transdisciplinary Journal of Engineering Science, 9, 182-198. https://doi.org/10.22545/2018/00109

[9] Bergh, A., \& Sloboda, J. (2010). Music and art in conflict transformation: A review. Music and Arts in Action, $2(2), 2-18$.

[10] Versluis, A.,\& Nicolescu, B. (2018). Transdisciplinarity and consciousness: Toward an integrated model. Transdisciplinary Journal of Engineering and Science, 9, 12-22. https://doi.org/10.22545/2018/00098 
[11] Brenner, J. E. (2008). The logic of transdisciplinarity. In B. Nicolescu (Ed.), Transdisciplinary theory and practice (pp.155-163). Cresskill, NJ: Hampton Press.

[12] Nicolescu, B. (Ed.). (2008b). Transdisciplinary theory and practice. Cresskill, NJ: Hampton Press.

[13] Nicolescu, B. (2008a). The idea of Levels of Reality and its relevance for non-reduction and personhood. Keynote at International Congress on Subject, Self, and Soul: Transdisciplinary Approaches to Personhood. Madrid, Spain. https://www.metanexus.net/idea-levels-reality-and-its-relevance-non-reduction-and-personhood/

[14] Nicolescu, B. (1999). Cyberspace et transhumanisme. In V. Fagone (Ed.), L'Art Vidéo, 1980-1999 (pp. 323-346). Milan, Italy: Mazzotta.

[15] Spacetime. (2020, July 10). In Wikipedia. Retrieved July 19, 2020 from https://en.wikipedia.org/wiki/Spacetime

[16] Harper, D. (2020). Online etymology dictionary. Retrieved from http://www.etymonline.com/

[17] Gibbs, P., Ylijoki, O-H, Guzmán-Valenzuela, C., \& Barnett, R. (2014) Universities in the flux of time. London, England: Routledge.

[18] Wells, H. G. (1895). The time machine. New York, NY: Henry Holt \& Co.

[19] Liang. T. Y. (2017). Complexity-intelligence strategy. Singapore: World Scientific.

[20] Anderson, S. (Ed.). (2014). Collins English dictionary (12th ed.). Glasgow, Scotland: Harper Collins.

[21] Mihalache, A. (2002). The cyber-space-time continuum: Meaning and metaphor. Information Society, 18, 293-301. https://doi.org/10.1080/01972240290075138

[22] Gálik, S., \& Tolnaiová, S. G. (2019). Cyberspace as a new existential dimension of man. In E. Abu-Taieh (Ed.), Cyberspace. IntechOpen E-Platform. Retrieved from http://dx.doi.org/10.5772/intechopen.88156

[23] Brenner, J. E. (2003). Logic, art and transdisciplinarity: A new logic for the new reality. Technoetic Arts, 1(3), 169-180. doi:10.1386/tear.1.3.169/1

[24] Wheeler, J. A. (1955). Geons. Physical Review, 97(2), 511-536. doi:10.1103/PhysRev.97.511

[25] Wilczek, F. [Speaker]. (2010, March 4). The J. Robert Oppenheimer lecture: Anticipating a new golden age [YouTube video]. Retrieved from https://www.youtube.com/watch?v=914jzZ4LXcU\&t=2887

[26] Lemos, R. T. S., \& Kern, V. M. (2009). Technontologies, complexity and hybrid interfaces. TripleC: communication, capitalism \& critique, 7(1), 29-37.

[27] Ranadivé, V. (2003, February 19). Hyperconnectivity: The future is here [Web log post]. Retrieved from https://www.forbes.com/sites/vivekranadive/2013/02/19/hyperconnectivity-the-future-isnow/\#574be04a30ad

[28] Wellman, B. (2001). Physical place and cyber place: The rise of networked individualism. International Journal of Urban and Regional Research, 25(2), 227-522. doi:10.1111/1468-2427.00309

[29] Madni, A. M. (2019). Transdisciplinary systems engineering: Exploiting disciplinary convergence to address grand challenges. IEEE Systems, Man, and Cybernetics Magazine, 5(2), 6-11. doi:10.1109/MSMC.2019.2899957

[30] Barbatsis, G., Fegan, M., \& Hansen, K. (1999). The performance of cyberspace: An exploration into computermediated reality. Journal of Computer-Mediated Communication, 5(1). https://doi.org/10.1111/j.10836101.1999.tb00332.x

[31] Iteanu, A. (1990). The concept of the person and the ritual system. An Orokaiva view. Man, New Series, 25(1), 35-53.

[32] Turner, V. (1974). Liminal to liminoid, in play, flow, and ritual: An essay in comparative symbology. Rice University Studies, 60(3), 52-92.

[33] Tirosh-Samuelson, H. (2007). Templeton research lecture: Facing the challenges of transhumanism: Philosophical, religious, and ethical considerations. Retrieved from Arizona State University website: http://transhumanism.asu.edu/pdf/2007_news_challenges.pdf

[34] Rohmann, C. (1999). A world of ideas. New York, NY: Ballantine Books.

[35] Bostrom, N. (2005). A history of transhumanist thought. Journal of Evolution and Technology, 14(1). https://www.nickbostrom.com/papers/history.pdf

[36] Maslow, A. H. (1969). The farther reaches of human nature. Journal of Transpersonal Psychology, 1(1), 1-9. 
Sue L. T. McGregor and Paul Gibbs

Being in the Hidden Third: Insights into Transdisciplinary Ontology

[37] Cerma, R. (2008). Transdisciplinary approach in therapy. In B. Nicolescu (Ed.), Transdisciplinarity (pp. 165-171). Cresskill, NJ: Hampton Press.

[38] Koltko-Rivera, M. E. (1998). Maslow's 'transhumanism': Was transpersonal psychology conceived as 'a psychology without people in it'? Journal of Humanistic Psychology, 38(1), 71-80. https://doi.org/10.1177/00221678980381007

[39] Nicolescu, B. (2010a, June 16-19). Disciplinary boundaries - What are they and how they can be transgressed? Paper prepared for the International Symposium on Research Across Boundaries. Luxembourg: University of Luxembourg. http://basarab-nicolescu.fr/Docs_articles/Disciplinary_Boundaries.htm

[40] Van Gulick, R. (2014). Consciousness. In E. N. Zalta (Ed.), Stanford encyclopedia of philosophy. Stanford, CA: Stanford University. https://plato.stanford.edu/entries/consciousness/

[41] Nicolescu, B. (2005, September 5-9). Transdisciplinarity: Past, present and future. Paper presented at the Second World Congress of Transdisciplinarity. Vitoria, Brazil.

[42] Koltko-Rivera, M. E. (2006). Rediscovering the later version of Maslow's hierarchy of needs: Self-transcendence and opportunities for theory, research, and unification. Review of General Psychology, 10(4), 302-317. https://doi.org/10.1037/1089-2680.10.4.302

[43] McGregor, S. L. T. (2004). Nature of transdisciplinary research and practice. Kappa Omicron Nu Human Sciences Working Paper Series. Http://www.kon.org/hswp/archive/transdiscipl.html

[44] Luhmann, C. C., \& Ahn, W. K. (2005). The meaning and computation of causal power: Comment on Cheng (1997) and Novick and Cheng (2004). Psychological Review, 112(3), 685-707. https://doi.org/10.1037/0033295X.112.3.685

[45] Leavy, P. (2011). Essentials of transdisciplinary research. Walnut Creek, CA: Left Coast.

[46] Augsburg, T. (2014) Becoming transdisciplinary: The emergence of the transdisciplinary individual. World Futures, 70(3-4), 233-247. https://doi.org/10.1080/02604027.2014.934639

[47] Humphreys, P. (2005). Emergence. In Encyclopedia.com. https://www.encyclopedia.com/social-sciences-andlaw/sociology-and-social-reform/sociology-general-terms-and-concepts/emergence

[48] Humphreys, P. (2016). Emergence. Oxford, England: Oxford University Press.

[49] Turner, W. (1911). Metaphysics. In C. G. Herbermann (Ed.), Catholic encyclopedia. New York, NY: Robert Appleton. Retrieved from https://www.newadvent.org/cathen/10226a.htm

[50] Faber, L. (2011, March 29). Transcendentals [Web log post]. Retrieved from http://lyfaber.blogspot.com/2011/03/trancendentals.html

[51] Goris, W. (2019). Transcendentals. In E. N. Zalta (Ed.), Stanford encyclopedia of philosophy. Retrieved from https://plato.stanford.edu/entries/transcendentals-medieval/

[52] Aertsen, J. A. (1998). Being and one: The doctrine of the convertible transcendentals in Duns Scotus. Franciscan Studies, 56, 47-64. doi:10.1353/frc.1998.0012

[53] Duns Scotus, J. (2005). John Duns Scotus: Early Oxford lecture on individuation (A. B. Wolter, Trans). New York, NY: Franciscan Institute.

[54] Aristotle. (1984). Metaphysics. In J. Barnes (Ed.), The complete works of Aristotle: The revised Oxford translation (pp. 1552-1728). Princeton, NJ: Princeton University Press.

[55] Fleetwood, S. (2009). The ontology of things, powers and properties. Journal of Critical Realism, 8(3), 343-366.

[56] Merriam-Webster. (n.d.). Mystical. In Merriam-Webster.com dictionary. Retrieved July 20,2020 from https://www.merriam-webster.com/dictionary/mystical

[57] Gibbs, P., \& Beavis, A. (2020). Contemporary thinking on transdisciplinary knowledge: What those who know, know. Switzerland: Springer.

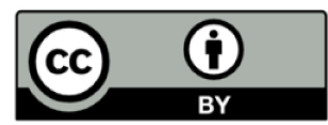


Copyright (c) 2019 by the authors. This is an open access article distributed under the Creative Commons Attribution License (https://creativecommons.org/licenses/by/4.0/), which permits unrestricted use, distribution, and reproduction in any medium, provided the original work is properly cited.

\section{About the Authors}

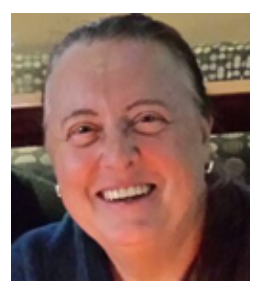

Dr. Sue L. T. McGregor (PhD, IPHE, Professor Emerita) is a Canadian home economist (nearly 50 years) retired after 30 years from Mount Saint Vincent University, Halifax NS. She has a keen interest in home economics philosophy and leadership along with transdisciplinarity, research paradigms and methodologies, and consumer studies and education. She is a ATLAS Fellow, a Rhoda H. Karpatkin International Consumer Fellow, and she received the TOPACE International Award (Berlin) for distinguished international consumer scholar, especially as consumer educator using a transdisciplinary perspective. Dr. McGregor is the recipient of Kappa Omicron Nu's (KON) Marjorie M. Brown Distinguished Professor Award (home economics leadership) and is Docent in Home Economics at the University of Helsinki (lifetime appointment in recognition of international leadership). She published Understanding and Evaluating Research (SAGE) in 2018. Her scholarship is at www.consultmcgregor.com

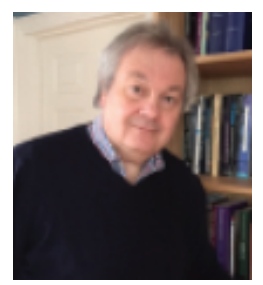

Dr. Paul Gibbs is Professor and Director of the Doctoral School, East European University. He is professor emeritus at Middlesex University, founder of the Centre for Education Research and Scholarship, and visiting professor at UTS Sydney and Azerbaijan university. His is a fellow of ATLAS as well as the Centre for Higher Education Policy, New College Oxford. He is an educator and researcher having taught notions of transdisciplinarity alongside social realism and Heideggerian hermeneutics. He has over 30 successful transdisciplinary professional doctorate students. He has published 20 books on topics ranging from the marketing of higher education to vocationalism and higher education and has published more than 100 academic articles. His particular approach to transdisciplinarity is informed by the works of Heidegger, Duns Scotus, and Deleuze and the theoretical insights of Basarab Nicolescu. He is also the series editor of SpringerBriefs on Key Thinkers in Education. 